\title{
Managing physician shortages: We are not doing enough
}

$\mathrm{C}$ anada is rich in information about our physician shortage but poor on concrete progress. We have a wealth of studies on care delivery models and proffered solutions from associations and governments, yet we continue to have a substantial and unmet need for health services in many regions of the country. Internationally, it seems that no country has it right. In the United States, there are calls for a $30 \%$ increase in the number of positions in medical schools. In some African countries, there is a dire shortage of physicians, ${ }^{1}$ yet some European countries have a surplus. Conservative estimates suggest that Canada needs at least 5000 more doctors in active practise. Changing the model of care and increasing the efficiency of the health care system will not be enough to alter this substantial shortfall. Shortages exist across all geographic regions - this is not only a rural problem - and across all disciplines, including family physicians, anesthetists, geriatricians and cancer care specialists.

In the interest of long-term sustainability, Canada must be self-sufficient: we must produce enough doctors to meet our needs, recognizing the important contribution of international medical graduates, the changing demographic and workload of the medical profession, as well as the introduction of other health care providers. Though we have had many discussions about self-sufficiency, we have not taken a collective approach to defining it and making decisions within a framework that puts it in the centre of the planning process. One of the inherent difficulties in forecasting and planning is the multitude of parameters that can affect predictions of physician resource needs. In the equation, there are variables such as physician numbers, both overall and within disciplines, their geographic distribution, their workload and the system in which they work. Despite the complexities, a number of straightforward and widely accepted measures would begin to address the current physician shortage. In this issue of $C M A J$, Phillips and colleagues examine the movement of Canadian-educated doctors to and from the United States and suggest potential ways to address the shortfall of Canadian doctors, especially in rural Canada. ${ }^{2}$

Phillips argues that we are losing too many physicians to the United States. Although this exodus has abated somewhat, we need to further understand the reasons for this ongoing loss and find ways to encourage these physicians to practise in Canada. Repatriation of these physicians will make a small but important contribution to our physician resources.

As a first step, if we are to recruit from other countries, whether from south of the border or from countries with limited health resources, we must develop recruiting practices that are ethically sound. Introducing more international medical graduates into our health care system is necessary, yet it pres- ents significant challenges. These challenges require a funded national strategy that includes a standardized assessment program to identify international medical graduates who are ready to practise, those who require additional training and those who would be better suited to other health care professions. We must also address the fact that integrating more international medical graduates into our education system further burdens our overtaxed system; we must ensure that there is increased funding for the infrastructure and additional teachers. Finally, self-sufficiency begins at home by admitting more Canadian students to medical school. We are approaching 2500 medical school positions in Canada, but we need 3000 positions as quickly as possible. This $20 \%$ increase will stretch our educational system tremendously. The current need for additional teachers and resources highlights the fact that this expansion must be carefully planned. We must ensure that our medical schools receive adequate support to manage increased enrolment and to maintain high-quality education.

The issues associated with becoming self-sufficient reinforce the complexity of physician human resource planning. As has been stated many times, ${ }^{3,4}$ there continues to be an obvious need for a pan-Canadian multi-stakeholder physician resource planning mechanism. What is preventing this critical step from being taken? Leadership. We need action now. The federal, provincial and territorial governments must quickly devise an action plan and fund it to address our shortages. Further study will lead only to more analysis-paralysis, not to meaningful health care improvements for Canadians.

\section{Nick Busing}

President and CEO

Association of Faculties of Medicine of Canada

Ottawa, Ont.

In collaboration with the Editorial-Writing Team

(Paul C. Hébert, Matthew Stanbrook, Barbara Sibbald,

Ken Flegel, Noni McDonald and Amir Attaran)

This article has been peer reviewed.

\section{REFERENCES}

I. World Health Organization. Working together for health: The world health report 2006. Geneva: World Health Organization; 2006. Available: www.who.int/ whr/2006 (accessed 2007 Mar 8).

2. Phillips RL Jr, Peterson S, Fryer GE Jr, et al. The Canadian contribution to the US physician workforce. $C M A J$ 2007;176(8):1083-7.

3. Health Council of Canada. Health care renewal in Canada: measuring up? Annual report to Canadians. Toronto: Health Council of Canada; 2007. Available: www .healthcouncilcanada.ca/docs/rpts/2007/HCC_MeasuringUp_2007ENG.pdf (accessed 2007 Mar 8).

4. Task Force Two. A Physician Human Resource Strategy for Canada. A physician human resource strategy for Canada: Final report. Ottawa: Task Force Two: A Physician Human Resource Strategy for Canada;2006. Available: www.physicianhr .ca/reports/TF2FinalStrategicReport-e.pdf (accessed 2007 Mar 8). 